\title{
ANALISIS KEMAMPUAN KONEKSI MATEMATIS SISWA SMK PADA MATERI FUNGSI KELAS XI
}

\author{
Arpin Chronika Saida Manalu ${ }^{1}$, Asri Septiahani ${ }^{2}$, Bunga Permaganti ${ }^{3}$ Melisari $^{4}$, Yeti Jumiati ${ }^{5}$, Wahyu \\ Hidayat \\ 1,2,3,4,5,6 IKIP SILIWANGI, JL. Terusan Jendral Sudirman, Cimahi, Jawa Barat, Indonesia \\ Arpinchronika240@gmail.com
}

\begin{abstract}
This research is a descriptive study that aims to analyze how the mathematical connection capabilities possessed by students of class XI vocational schools on the function material. The subjects of this study were 15 students of class XI at SMK Kartini Bhakti Mandiri. The instrument used in this study was in the form of 3 questions that referred to the indicators of students mathematical connection abilities. The data analysis technique used is to assess the results of student answers and determine the percentage criteria for errors made by students. The results of this study indicate that students mathematical connection abilities fall into the medium category, which can be seen from the percentage of errors made by students on indicators to recognize and apply mathematics in contexts outside mathematics.
\end{abstract}

Keywords: Mathematical connection capabilities, functions

\begin{abstract}
Abstrak
Penelitian ini merupakan penelitian deskriptif yang bertujuan untuk menganalisis bagaimana kemampuan koneksi matematis yang dimiliki oleh siswa SMK kelas XI pada materi fungsi. Subjek dari penelitian ini adalah 15 orang siswa kelas XI di SMK Kartini Bhakti Mandiri. Instrumen soal yang digunakan dalam penelitian ini berupa 3 buah soal yang mengacu pada indikator kemampuan koneksi matematis siswa. Teknik menganalisis data yang dilakukan yaitu menilai hasil jawaban siswa dan menentuka kriteria persentase kesalahan yang dilakukan oleh siswa. Hasil dari penelitian ini menunjukkan bahwa kemampuan koneksi matematis siswa tergolong dalam kategori sedang, yang terlihat dari persentasi kesalahan yang dilakukan siswa pada indikator mengenali dan menerapkan matematika dalam kontek-konteks di luar matematika.
\end{abstract}

Kata kunci: Kemampuan koneksi matematis, fungsi

\section{PENDAHULUAN}

Matematika merupakan salah satu pelajaran yang penting diberikan bagi siswa, mengingat banyaknya manfaat dan keuntungan yang akan seseorang rasakan jika ia dapat memahami matematika dengan baik. Hal ini sejalan dengan yang di sampaikan oleh Putra (2018), bahwa matematika merupakan salah satu pelajaran yang pentigg diberikan kepada siswa. Juga sejalan dengan yang disampaikan oleh Zulfah (2019), bahwa setiap individu yang memiliki penguasaan matematika akan memberikan kemudahan dan kegunaan yang beragam. Matematika juga merupakan ilmu dasar yang penting untuk dimiliki oleh siswa agar terciptanya ketertiban dalam aktivitas sehari-hari (Manalu \& Zanthy, 2020).

Banyak orang terkadang tidak menyadari akan pentingnya matematika ini karena dianggap sulit, sehingga tidak ingin mempelajari lebih banyak lagi materi-materi yang ada dalam matematika yang tentu memiliki banyak kegunaan jika diterapkan dalam kehidupan sehari-hari. Matematika ialah ilmu yang identik dengan rumus-rumus serta perhitungan-perhitunga (Manalu, Jumiati, \& Setiawan, 2019). Namun walaupun identik dengan rumus dan perhitungan tetapi tidak berarti semua hanya tentang rumus juga perhitungan. Banyak hal yang dapat diperoleh dan kemudian bisa diterapkan dalam kehidupan sehari-hari dengan mempelajari matematika. Dengan belajar matematika kita juga akan 
Analisis Kemampuan Koneksi Matematis Siswa SMK Pada Materi Fungsi Kelas XI, Arpin Chronika Saida Manalu, Asri

memperoleh dan dapat mengembangkan berbagai keterampilan baik hard skill maupun soft skill, salah satunya adalah kemampuan koneksi matematika.

Menurut NCTM (Imamuddin, Isnaniah, Putra, \& Rahmadila, 2019), koneksi matematis merupakan bagian penting yang harus memperoleh penekanan disetiap jenjang pendidikan. Kemampuan koneksi matematis yang baik akan membantu siswa untuk memahami hubungan antara berbagai konsep dalam matematika dan mengaplikasikanya dalam kehidupan sehari-hari, sehingga keterampilan ini penting untuk dibangun dan dipelajari (Siagian, 2016). Menurut NCTM (Dinda Nurul Adni, Puji Nurfauziah, 2018), apabila siswa telah mampu menghubungkan topik-topik antar matematika maka pemahaman matematikanya akan semakin dalam dan bertahan lama karena siswa mampu melihat hubungan antar topik matematika dalam konteks diluar matematika juga dalam pengalaman kehidupan sehari-hari. Kemampuan koneksi tentu penting dimiliki oleh siswa untuk memudahkan siswa menerapkan apa yang dipelajari dalam situasi kehidupan sehari-hari, sehingga apa yang dipelajari oleh siswa tidak hanya untuk dihafal.

Adapun indikator kemampuan koneksi menurut NCTM (National Council of Teacher of Mathematics) (2000: 64): (a) Mengenali dan memanfaatkan hubungan-hubungan antara gagasan dalam matematika; (b) Memahami bagaimana gagasan-gagasan dalam matematika saling berhubungan dan mendasari satu sama lain untuk menghasilkan suatu keutuhan koheren; (c) Mengenali dan menerapkan matematika dalam kontek-konteks di luar matematika.

Kemampuan koneksi yang dimiliki oleh siswa khususnya siswa SMK tentu berbeda-beda yang dapat disebabkan oleh berbedanya pemahaman yang dimiliki oleh setiap siswa itu sendiri. Hal tersebut sejalan dengan yang disampaikan oleh Supriyadi, Suharto, \& Hobri (2017), yaitu "The higher the level of mathematical ability of students the higher the ability of mathematical connections", dimana semakin tinggi tingkat kemampuan matematis yang dimiliki oleh siswa, semakin tinggi pula pemahaman koneksi yang akan dimilikinya. Siswa yang memiliki kemampuan matematis yang tinggi akan memiliki kemampuan koneksi matematis yang tinggi juga, begitu juga sebaliknya siswa yang memiliki kemampuan matematis yang rendah juga akan memiliki kemampuan koneks matematis yang rendah pula. Salah satu materi yang penting untuk dipelajari oleh siswa SMK adalah materi fungsi. Dengan adanya kemampuan koneksi matematis yang baik, tentu siswa akan mudah menghubungkan hasil pemahamannya pada materi fungsi ini kedalam bidang lain serta dalam kehidupan sehari-hari.

Berdasarkan uraian di atas, peneliti tertarik untuk melakukan penelitian terhadap kemampuan koneksi matematis siswa di jenjang SMK. Penelitian ini bertujuan untuk mengetahui bagaimana kemampuan koneksi matematis siswa SMK kelas XI pada materi fungsi dengan menggunakan soal sesuai dengan indikator kemampuan koneksi. Sehingga peneliti mengambil judul "Analisis Kemampuan Koneksi Matematis Siswa SMK pada Materi Fungsi kelas XI". 


\section{METODE}

Penelitian ini menggunakan metode deskriptif Asrinan (2015). Abdurrahman (Warih, Parta, \& Rahardjo, 2016), mengatakan penelitian deskriprif memiliki tujuan untuk menggambarkan sifat suatu individu, kelompok, gejala maupun suatu keadaan secara tepat. Sampel yang dipakai dalam penelitian yang diteliti ini yaitu siswa kelas XI semester II di SMK Kartini Bhakti Mandiri. Indikator kemampuan koneksi matematika yang digunakan terdiri dari 3 buah butir soal yang sesuai dengann indikator koneksi menurut NCTM (National Council of Teacher of Mathematics) (2000: 64): (a) Mengenali dan memanfaatkan hubungan-hubungan antara gagasan dalam matematika; (b) Memahami bagaimana gagasan-gagasan dalam matematika saling berhubungan dan mendasari satu sama lain untuk menghasilkan suatu keutuhan koheren; (c) Mengenali dan menerapkan matematika dalam kontekkonteks di luar matematika. Tes kemampuan pada kemampuan koneksi dalam matematik terdiri dari tiga pertanyaan yang masing-masing pertanyaan mewakili satu indikator dengan masing-masing skor maksimal 4. Tes kemampuan koneksi matematis ini diujikan kepada 15 orang siswa. Teknik menganalisis data yang dilakukan terdiri dari menilai jawaban siswa berdasarkan tes yang diberikan, menentukan jenis-jenis kesalahan jawaban oleh siswa dan mengetahui banyaknya jenis kesalahan siswa digunakan suatu rumus presentase berikut.

$\mathrm{P}=\frac{n}{N} \times 100$

Keterangan:

$\mathrm{P}=$ Presentase

$\mathrm{n}=$ Banyaknya kesalahan

$\mathrm{N}=$ Banyaknya kemungkinan kesalahan

Kriteria presentase banyaknya kesalahan dari masing-masing jenis kesalahan, konversi skor merujuk dari Nurkanca \& Sunarta (Faelosofi, 2017)

\section{Tabel 1.}

Kriteria Presentase Banyaknya Kesalahan Presentase (P) Kriteria

\begin{tabular}{ll}
\hline Presentase $(\mathrm{P})$ & Kriteria \\
\hline $90,00 \leq \mathrm{P} \leq 100$ & Sangat Tingi \\
$80,00 \leq \mathrm{P}<90,00$ & Tinggi \\
$65,00 \leq \mathrm{P}<80,00$ & Sedang \\
$55,00 \leq \mathrm{P}<65,00$ & Rendah \\
$\mathrm{P}<55,00$ & Sangat rendah \\
\hline
\end{tabular}


Analisis Kemampuan Koneksi Matematis Siswa SMK Pada Materi Fungsi Kelas XI, Arpin Chronika Saida Manalu, Asri Septiahani, Bunga Permaganti, Melisari, Yeti Jumiati, Wahyu Hidayat

\section{HASIL}

Hasil analisis data kemampuan koneksi matematis siswa diperoleh dengan mengujikan siswa dengan 3 butir soal yang sesuai dengan indikator kemampuan pemahaman koneksi siswa menurut NCTM (National Council of Teacher of Mathematics) (2000: 64), yaitu sebagai berikut:

(1) Suatu peluru ditembakkan ke atas. Tinggi peluru pada saat $t$ detik dirumuskan oleh $h(t)=40 t-5 t^{2}$ (dalam satuan meter). Tinggi maksimum yang dapat ditempuh oleh peluru tersebut adalah .....

(2) Dua orang berangkat pada waktu yang sama dan adari tempat yang sama, serta bepergian melalui jalan-jalan yang saling tegak lurus. Seseorang bepergian dengan kecepatan $4 \mathrm{~km} / \mathrm{jam}$ lebih cepat dari yang lainnya. Setelah 2 jam mereka terpisah pada jarak $40 \mathrm{~km}$. Tentukanlah jumlah jarak yang ditempuh kedua orang tersebut!

(3) Sebuah lapangan berbentuk persegi panjang. Diketahui panjangnya dua kali lebarnya. Pada tepi sebelah luar tiga sisi lapangan tersebut dibuat jalan yang lebarnya 2 meter. Jika luas seluruh jalan ( yang diarsir pada gambar) adalah $128 \mathrm{~cm}^{2}$, maka luas lapangan tersebut adalah .....

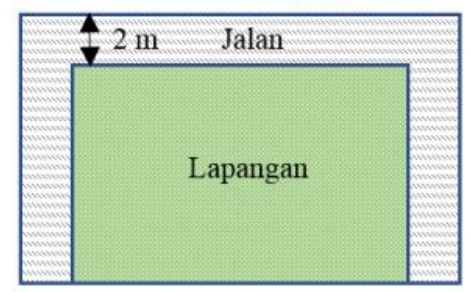

Berikut ini adalah tabel perolehan skor siswa setiap butir soal :

Tabel 2.

Persentase (P) Perolehan Skor Siswa Tiap Butir Soal

\begin{tabular}{llccccc}
\hline NO & NAMA SISWA & \multicolumn{3}{c}{ NOMOR SOAL } & $\begin{array}{c}\text { SKOR } \\
\text { TOTAL }\end{array}$ & NILAI \\
\hline 1 & siswa 1 & 3 & $2(4)$ & $3(4)$ & 7 & 58,33 \\
2 & siswa 2 & 2 & 3 & 1 & 5 & 41,67 \\
3 & siswa 3 & 3 & 3 & 2 & 8 & 66,67 \\
4 & siswa 4 & 3 & 3 & 2 & 8 & 66,67 \\
5 & siswa 5 & 1 & 1 & 0 & 2 & 16,67 \\
6 & siswa 6 & 3 & 3 & 2 & 8 & 66,67 \\
7 & siswa 7 & 2 & 2 & 1 & 5 & 41,67 \\
8 & siswa 8 & 2 & 2 & 2 & 6 & 50 \\
9 & siswa 9 & 2 & 2 & 1 & 5 & 41,67 \\
10 & siswa 10 & 3 & 3 & 2 & 8 & 66,67 \\
11 & siswa 11 & 3 & 3 & 2 & 8 & 66,67 \\
12 & siswa 12 & 3 & 3 & 1 & 7 & 58,33 \\
13 & siswa 13 & 2 & 2 & 1 & 5 & 41,67 \\
14 & siswa 14 & 1 & 1 & 0 & 2 & 16,67 \\
15 & siswa 15 & 3 & 3 & 2 & 8 & 66,67 \\
\hline & JUMLAH & 36 & 36 & 20 & & \\
\hline & P Benar (\%) & 60 & 60 & 33,33 & & \\
\hline & P Salah (\%) & 40 & 40 & 66,67 & \\
\hline
\end{tabular}


Dari 15 siswa yang memberikan jawabannya pada ketiga indikator soal yang telah disajikan diperoleh hasil jawaban yang beragam dengan nilai yang berbeda-beda pada setiap indikator soal tes nya seperti yang telah disajikan pada tabel 2 di atas. Setelah dilakukan penilaian pada jawaban siswa, kemudian dihitung berapa persentase kesalahan yang dilakukan oleh siswa untuk menganalisis bagaimana kemampuan koneksi matematis yang dimiliki oleh siswa khususnya siswa SMK kelas XI. Berikut ini disajikan rata-rata persentase ketiga indikator:

\section{Tabel 3.}

Persentase (P) Banyaknya Kesalahan Jawaban

\begin{tabular}{|l|c|l|l|}
\hline \multicolumn{1}{|c|}{ Indikator } & P Benar & P Salah & Kriteria Kesalahan \\
\hline $\begin{array}{l}\text { Mengenali dan memanfaatkan hubungan- } \\
\text { hubungan antara gagasan dalam matematika. }\end{array}$ & 60 & 40 & Sangat rendah \\
\hline $\begin{array}{l}\text { Memahami bagaimana gagasan-gagasan } \\
\text { dalam matematika saling berhubungan dan } \\
\text { mendasari satu sama lain untuk } \\
\text { menghasilkan suatu keutuhan koheren. }\end{array}$ & 60 & 40 & Sangat rendah \\
\hline $\begin{array}{l}\text { Mengenali dan menerapkan matematika } \\
\text { dalam kontek-konteks di luar matematika. }\end{array}$ & 33,33 & 66,67 & Sedang \\
\hline
\end{tabular}

Berdasarkan Tabel 3, dapat dilihat bahwa sesuai dengan kriteria persentase banyaknya kesalahan, tingkat kesalahan siswa pada indikator mengenali dan memanfaatkan hubungan-hubungan antara gagasan dalam matematika berada pada kriteria sangat rendah yaitu hanya $40 \%$, begitu juga dengan indikator memahami bagaimana gagasan-gagasan dalam matematika saling berhubungan dan mendasari satu sama lain untuk menghasilkan suatu keutuhan koheren yang juga berada pada kriteria sangat rendah yaitu memiliki persentasi kesalahan $40 \%$, kemudian pada indikator yang terakhir yaitu mengenali dan menerapkan matematika dalam kontek-konteks di luar matematika berada pada kriteria sedang dimana memiliki persentase kesalahan $66,67 \%$.

Berdasarkan hasil penelitian yang telah dilakukan dapat dilihat dari tabel 2 dan tabel 3, bahwa pada indikator soal yang pertama yaitu: mengenali dan memanfaatkan hubungan-hubungan antar gagasan dalam matematika, semua siswa dapat menjawa soal pada indikator ini namun tidak ada siswa yang dapat menyelesaikan soal ini dengan baik, siswa memberi jawaban yang bervariatif dan hampir mendekati jawaban benar. Selanjutnya pada indikator soal kedua yaitu: memahami bagaimana gagasangagasan dalam matematika saling berhubungan dan mendasari satu sama lain untuk menghasilkan suatu keutuhan koheren, pada jawaban siwa terlihat bahwa jawaban siswa bervariatif, semua siswa telah mampu memberikan jawaban yang hampir mendekati benar dan tidak membiarkan soal tidak diisi sama sekali atau bernilai 0 . Namun dari 15 siswa yang membubuhkan jawaban, tidak ada satupun siswa yang dapat memberikan jawaban yang benar dan baik. Dan selanjutnya pada indikator soal yang terakhir 
yaitu: mengenali dan menerapkan dalam kontek diluar matematika, indikator ini memiliki persentase kesalahan terbesar dari dua indikator sebelumnya, hal ini dapat terlihat dari hasil jawaban setiap siswa dimana ada 2 siswa yang sama sekali tidak bisa menjawab soal pada indikator ini dan 13 siswa lagi tidak menyelesaikan jawaban sampai selesai.

Dari jawaban siswa dari ketiga indikator soal, secara keseluruhan jika dilihat dari kesalahan yang dilakukan oleh siswa bahwa kemampuan koneksi yang dimiliki siswa tergolong pada kategori sedang.

\section{KESIMPULAN}

Dari hasil analisis kemampuan koneksi matematis siswa pada siswa SMK berdasarkan instrumen soal yang telah diujikan, kesalahan terbanyak jawaban siswa ada pada indikator "mengenali dan menerapkan matematika dalam kontek-konteks di luar matematika", sedangkan pada indikator dua lainnya memperoleh kriteria kesalahan sanagt rendah, sehingga dapat disimpulkan bahwa kemampuan koneksi matematis yang dimiliki oleh siswa sudah tergolong pada kategori sedang .

\section{DAFTAR PUSTAKA}

Asrinan. (2015). Deskripsi Cara Belajar dan Hasil Belajar Matematika Siswa yang Memiliki Orang Tua Tunggal di Kelas VIII SMPN 5 Parepare. Prosiding Seminar Nasional, 2.

Dinda Nurul Adni, Puji Nurfauziah, E. E. R. (2018). Analisis Kemampuan Koneksi Matematis Siswa SMP Ditinjau Dari Self-Efficacy Siswa. Jurnal Pembelajaran Matematika Inovatif, 1(5), $957-$ 964.

Faelosofi, R. (2017). Identifikasi Kemampuan Berpikir Kreatif Matematika Pokok Bahasan Peluang. Jurnal Edumath, 3(2), 155-163.

Imamuddin, M., Isnaniah, I., Putra, A., \& Rahmadila, R. (2019). Kemampuan Koneksi Matematika Siswa Dengan Pendekatan Kontekstual Di SMPN 1 Banuhampu. Al-Khwarizmi: Jurnal Pendidikan Matematika Dan Ilmu Pengetahuan Alam, 7(1), 11-22. https://doi.org/10.24256/jpmipa.v7i1.560

Manalu, A. C. S., Jumiati, Y., \& Setiawan, W. (2019). Analisis Minat Belajar Matematika Siswa SMP Kelas VIII pada Materi Persamaan Garis Lurus Berbantu Aplikasi Geogebra. 2(1), 63-69.

Manalu, A. C. S., \& Zanthy, L. S. (2020). Analisis Kesalahan Siswa SMP Kelas IX dalam Menyelesaikan Soal Materi Lingkaran. 4(1), 104-112.

Putra, H. D., Setiawan, H., Nurdianti, D., Retta, I., Desi, A., \& A. (2018). Kemampuan Pemahaman matematis siswa SMP di bandung barat. 11, 19-30.

Siagian, M. D. (2016). Kemampuan Koneksi Matematika Dalam Pembelajaran Matematika. Journal of Mathematics Education and Sciences, 2(1), 58-67.

Supriyadi, E. W. A., Suharto, S., \& Hobri, H. (2017). Analisis Kemampuan Koneksi Matematis Berdasarkan Nctm (National Council of Teachers of Mathematics) Siswa Smk Kelas Xi Jurusan 
Multimedia Pada Pokok Bahasan Hubungan Antar Garis. Kadikma, 8(1), 128-136.

Warih, P. D., Parta, I. N., \& Rahardjo, S. (2016). Analisis Kemampuan Koneksi Matematis Siswa Kelas VIII pada Materi Teorema Pythagoras. Prosiding Konferensi Nasional Penelitian Matematika Dan Pembelajarannya [KNIP I], (Knpmp I), 377-384.

Zulfah, Z. (2019). Analisis Kemampuan Peserta Didik Smp di Bangkinang Melalui Penyelesaian Soal Pisa 2015. Jurnal Cendekia: Jurnal Pendidikan Matematika, 3(2), 350-362. https://doi.org/10.31004/cendekia.v3i2.126 